\title{
Evaluating the Acoustic Benefits of Over-the-Rotor Acoustic Treatments Installed on the Advanced Noise Control Fan
}

\author{
Matthew R. Gazella ${ }^{1}$ \\ U.S. Air Force Research Laboratory, Aerospace Systems Directorate, Wright-Patterson AFB, Ohio, 45433 USA \\ Tamuto Takakura ${ }^{2}$ \\ University of Notre Dame, Notre Dame, Indiana, 46556, USA \\ Daniel L. Sutliff ${ }^{3}$ \\ NASA Glenn Research Center, Cleveland, Ohio, 44135, USA \\ Richard Bozak ${ }^{4}$ \\ NASA Glenn Research Center, Cleveland, Ohio, 44135, USA \\ Brian J. Tester ${ }^{5}$ \\ Institute of Sound \& Vibration, University of Southampton, SO17 1BJ UK
}

\begin{abstract}
Over the last 15 years, over-the-rotor acoustic treatments have been evaluated by NASA with varying success. Recently, NASA has been developing the next generation of over-the-rotor acoustic treatments for fan noise reduction. The NASA Glenn Research Center's Advanced Noise Control Fan was used as a Low Technology Readiness Level test bed. A rapid prototyped in-duct array consisting of 50 microphones was employed, and used to correlate the in-duct analysis to the far-field acoustic levels and to validate an existing beam-former method. The goal of this testing was to improve the Technology Readiness Level of various over-the-rotor acoustic treatments by advancing the understanding of the physical mechanisms and projecting the far-field acoustic benefit.
\end{abstract}

$\begin{array}{ll} & \text { Nomenclature } \\ \text { AAPL } & =\text { Aero-Acoustic Propulsion Laboratory } \\ \text { ADP } & =\text { Advanced Ducted Propulsor } \\ \text { ANCF } & =\text { Advanced Noise Control Fan } \\ C F A N S & =\text { Configurable Fan Artificial Source } \\ F M L & =\text { Foam-Metal-Liner } \\ H W & =\text { Hardwall } \\ \text { LSWT } & =\text { Low-Speed Wind-Tunnel } \\ O T R & =\text { Over-the-rotor } \\ O A S P L & =\text { Over-all Sound Power Level } \\ P W L & =\text { Acoustic Sound Power Level } \\ R P M_{C}= & \text { Revolutions-Per-Minute (Corrected) } \\ S D T & =\text { Source Diagnostic Test }\end{array}$

${ }^{1}$ Aerospace Engineer, High Speed Systems Division, AIAA Student Member.

${ }^{2}$ Postdoctoral Research Associate, Notre Dame Turbomachinery Laboratory, AIAA Student Member.

${ }^{3}$ Aerospace Engineer, Acoustics Branch, Associate Fellow, AIAA.

${ }_{5}^{4}$ Aerospace Engineer, Acoustics Branch, AIAA Member.

${ }^{5}$ Principal Research Fellow, Faculty of Engineering and the Environment, AIAA Senior Member. 


\section{Introduction}

NASA has been involved in several programs whose goals were to reduce the transport aircraft noise attributed to the turbofan engine. Reduction in aircraft noise is required to meet increasing noise regulations within the United States and other international locations.

A promising aircraft engine noise reduction concept is the over-the-rotor (OTR) acoustic treatment, embedded in the nacelle wall, and generally located at or near the fan rotor plane. OTR liners are believed to reduce fan noise radiated to the community via two mechanisms. First, it provides traditional absorption of acoustic waves propagating over the liner. Second, it provides a pressure-release surface in the near-field of the noise generation process, thereby modifying radiation efficiency. The harsh aeroacoustic environment has heretofore prevented conventional liner installation at this location. OTR liners have been evaluated by NASA over the last $15^{1}$ years with varying success ${ }^{2,3}$. OTR development was last pursued by NASA's Environmentally Responsible Aviation Project in May 2014.

Foam-Metal-Liners (FML) are one potential solution for a material suitable for the harsh OTR environment. The most promising FML tests, with $\sim 4-5 \mathrm{~dB}$ acoustic power level reductions, were on the Advanced Noise Control Fan Rig (ANCF) test in $2007^{4}$, as well as a Williams FJ44 Engine Test in $2008^{5}$. However, the benefit was not as significant (1-2dB OASPL) on the Advanced Ducted Propulsor (ADP) test in the 9x15 Low Speed Wind Tunnel (LSWT) in 2008. Recently, in 2013 increased noise levels were observed in a test with the Source Diagnostic Test (SDT) hardware (R4 fan) in the 9x15 LSWT. While acoustic results have varied, the aerodynamic performance penalty has been improved upon over the years. Fan efficiency losses were between negligible and $0.75 \%$ on the SDT/R4 ${ }^{2}$ and FJ $44^{5}$ tests, versus the $8-10 \%$ loss on the ADP and ANCF tests. The large pressure fluctuations found in the over-the-rotor environment have damaged both the acoustic treatments and fan blades. When these pressure fluctuations are dissipated within the acoustic treatment the increased temperature has also been found to damage the treatments.

In order to better understand the physical effects of over-the-rotor acoustic treatments, a series of tests were performed at multiple Technology Readiness Levels with various treatment concepts. As was done previously; the first testing was completed with 2-inch square treatment samples in the Normal Incidence Tube at NASA Langley Research Center. Four of the treatments and two baseline configurations were designed and fabricated for testing on the ANCF at NASA Glenn Research Center (GRC). Finally, the same configurations were tested in the W-8 Single Stage Compressor Facility at GRC using the SDT/R4 fan hardware. This paper presents the results of the over-therotor Acoustic Treatment Technology Development: Advanced Noise Control Fan Risk Reduction test. The goal was to measure the insertion loss of the 4 liners in the OTR configurations and compare to the same liners in the inlet, thereby providing some insight into the relative impact of the two-physical mechanisms mentioned earlier. Each liner was evaluated in the ANCF, and evaluated in terms of acoustic reduction efficacy. This provided a priority testing order for the upcoming W-8 test. A consensus of the physical mechanism of the OTR acoustic reduction has not been reached (source modification vs. acoustic attenuation).

In-duct arrays had not been used within the W8 Single-Stage Axial Compressor Facility, and validation of the inlet in-duct array to far-field directivity has not been demonstrated. The inlet in-duct array was evaluated operationally on the ANCF and used to correlate the in-duct analysis to the far-field acoustic levels. Since far-field acoustic measurements are not possible in $\mathrm{W}-8$, ANCF is the best candidate to provide the in-duct and far-field data required to develop a correlation or projection based on beamforming using the in-duct array ${ }^{6}$. Far-field levels are the definitive metric for acoustic evaluation.

\section{Discussion}

\section{A. Experimental Setup Overview}

The ANCF was built in the early 1990's to provide a convenient test bed to measure and understand fan-generated acoustics, duct propagation, and radiation in the far-field. The test bed was the ANCF $^{7,8,9}$ (shown in Figure 1) which is a 4-ft diameter low speed fan used for validation of noise reduction concepts. The ANCF is a highly configurable ducted fan rig located in the Aero-Acoustic Propulsion Laboratory (AAPL) ${ }^{10}$ (Figure 2). AAPL is a world-class facility providing outstanding testing services in aircraft noise reduction, engine nozzle and fan components acoustic and performance research. The laboratory is a 65 by 130 -foot diameter hemi-spherical dome fitted with acoustic foam wedges creating an anechoic environment down to $250 \mathrm{~Hz}$, ideal for acoustic testing. The nominal operating condition of the ANCF is $2000 \mathrm{RPM}_{\mathrm{C}}$ (420 ft/sec tip speed) providing an inlet duct Mach number of $\sim 0.15$. The 16-bladed fan generates a fundamental blade passing frequency of $\sim 500 \mathrm{~Hz}$. The ANCF is comprised of a series of 12 or 13-inchlong cylindrical spools that are axially interchangeable, enabling rapid testing of a variety of configurations. It has the ability to run rotor-alone in which no stator or inlet guide vanes are required for structural support. In this experiment, 
a 9-inch OTR/FML spool was used. Liner cores were fabricated in multiple sections for installation into the treatment spool. To facilitate fabrication of liner cores, accurate measurement of the OTR spool was required.
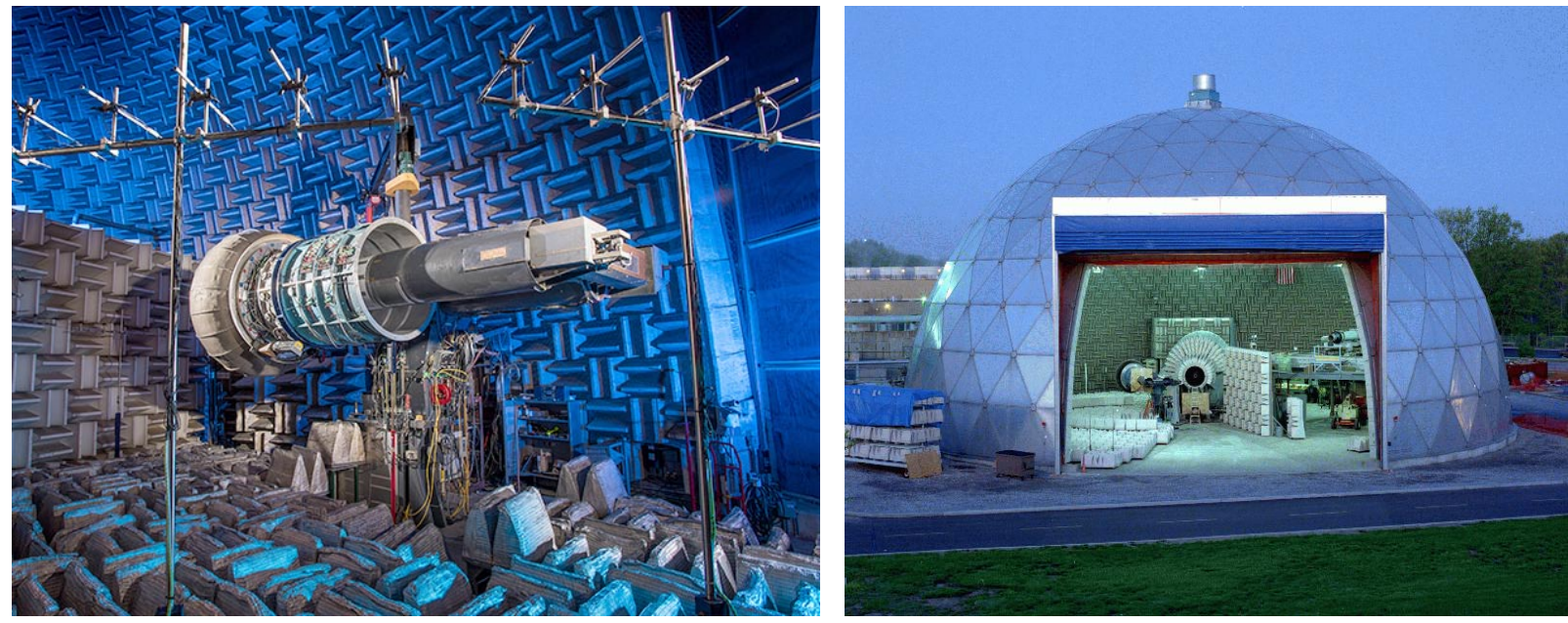

Figure 1 - Advanced Noise Control Fan.

Figure 2 -Aero-Acoustic Propulsion Laboratory.

\section{B. Liner}

A total of six liner configurations were tested on the ANCF rig. All configurations consist of sheets of Garolite G10 cut into arcs and layered axially to create a fan casing. The first two configurations did not contain treatment and were used to isolate the impact of circumferential grooves over the fan. The remaining four treated configurations have $0.5^{\prime \prime}$ deep circumferential grooves directly over the fan since this has been shown to reduce the aerodynamic performance loss associated with over-the-rotor treatments ${ }^{12}$. The first configuration was a hardwall baseline fan case (Configuration I). The second, Configuration II, contained seven circumferential grooves with a depth of 0.5 ", a groove width of $0.25 "$ ", and a rib width of $0.125 "$ ". In the four treated configurations, the acoustic treatments were added to the bottoms of the grooves. At the bottom of the grooves each grouping of thirteen $0.035^{\prime \prime}$ diameter holes led to a chamber measuring $0.25 "$ axially, $0.5 "$ circumferentially, and $1 "$ deep. In Configuration III, the perforate thickness was $0.06 "$ and the chambers were left empty. In Configuration IV, the perforate thickness was increased to 0.25 " and the chambers were left empty. In Configuration V, the perforate was 0.06 " thick and a series of increasingly penetrating fins were added in the chamber. In Configuration VI, the perforate was 0.06" and a foam metal (FeCrAlY) with 80ppi $8 \%$ was inserted into the chambers. Figure 3 shows the individual liner concepts. The configurations are listed in Table I.

TABLE I - Liner Configurations Tested

\begin{tabular}{|c|l|}
\hline CONFIGURATION ID & \multicolumn{1}{c|}{ DESCRIPTION } \\
\hline I & Hardwall \\
\hline II & Hardwall w/ Grooves \\
\hline III & Empty Chamber w/ Thin Face Sheet \\
\hline IV & Empty Chamber w/ Thick Face Sheet \\
\hline V & Expansion Chamber w/ Thin Face Sheet \\
\hline VI & Foam Metal w/ Thin Face Sheet \\
\hline
\end{tabular}

The test matrix began with an initial ANCF baseline test from 1400 to $2000 \mathrm{RPM}_{\mathrm{C}}$ to evaluate the in-duct array strip (Figure 4). ANCF configurations tested during the baseline runs consisted of 14 vanes or 0 vanes. Following the baseline, the six liner cores within the OTR/FML liner spool were tested individually, both in the inlet and OTR positions. During the OTR configurations, far-field and in-duct array data was acquired over a range of $1400-2000$ $\mathrm{RPM}_{\mathrm{C}}$. With the liner(s) in the inlet position, only far-field data were acquired. 

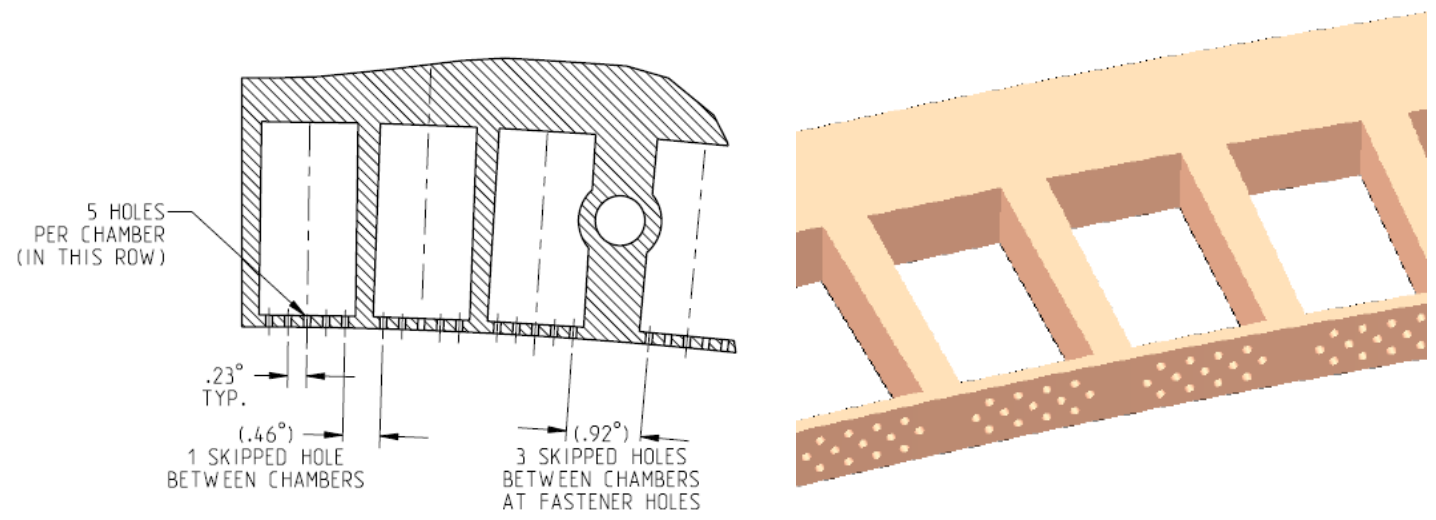

(a) Close-up of Liner Segment
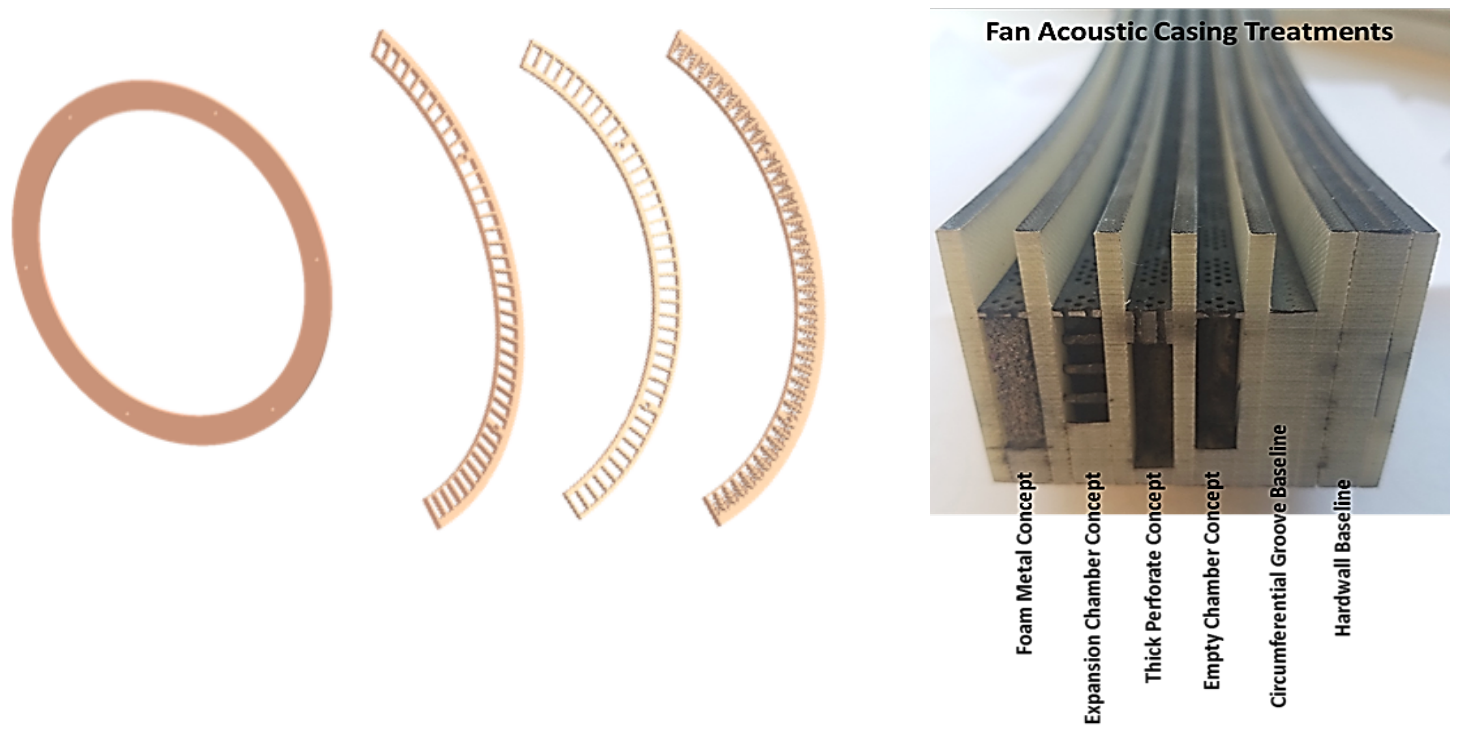

(b) Individual Segments of Liner

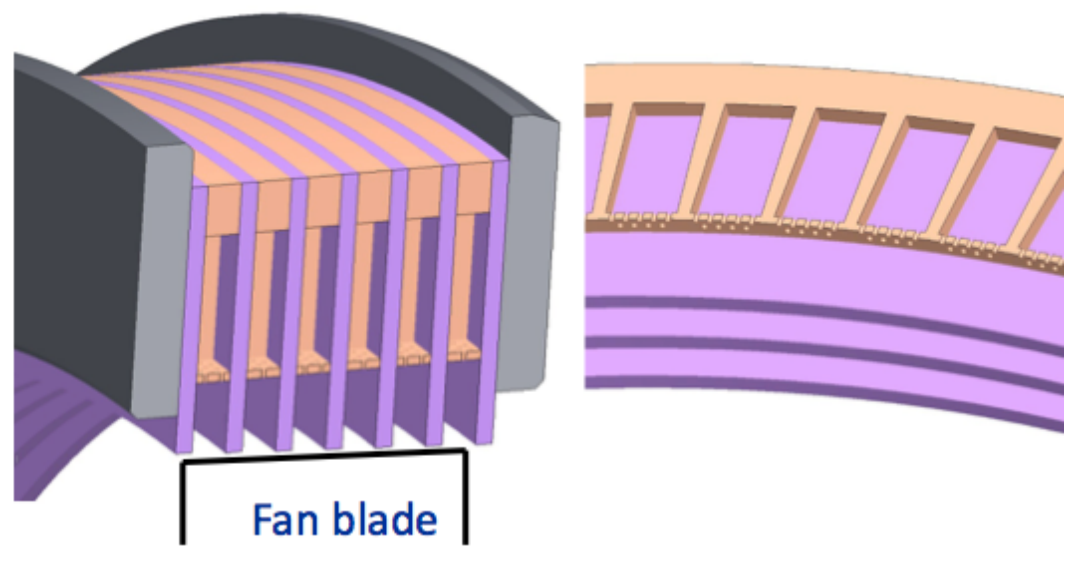

(c) Individual Segments of Liner

Figure 3: Liner Assembly. 


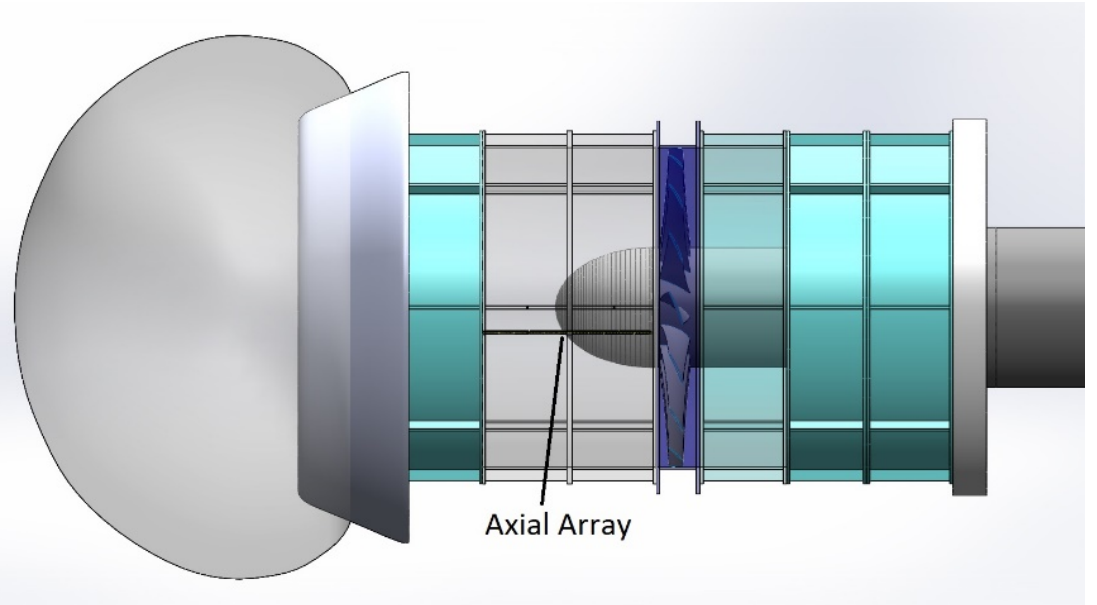

(a) Baseline (Hardwall)

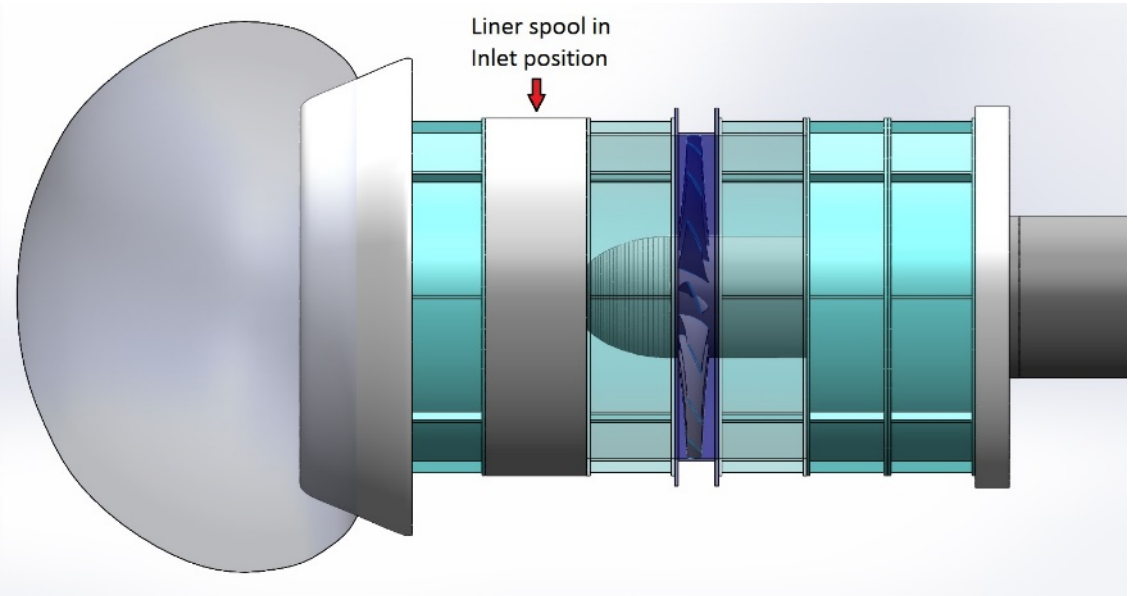

(b) Acoustic Treatment Spool in Inlet Position.

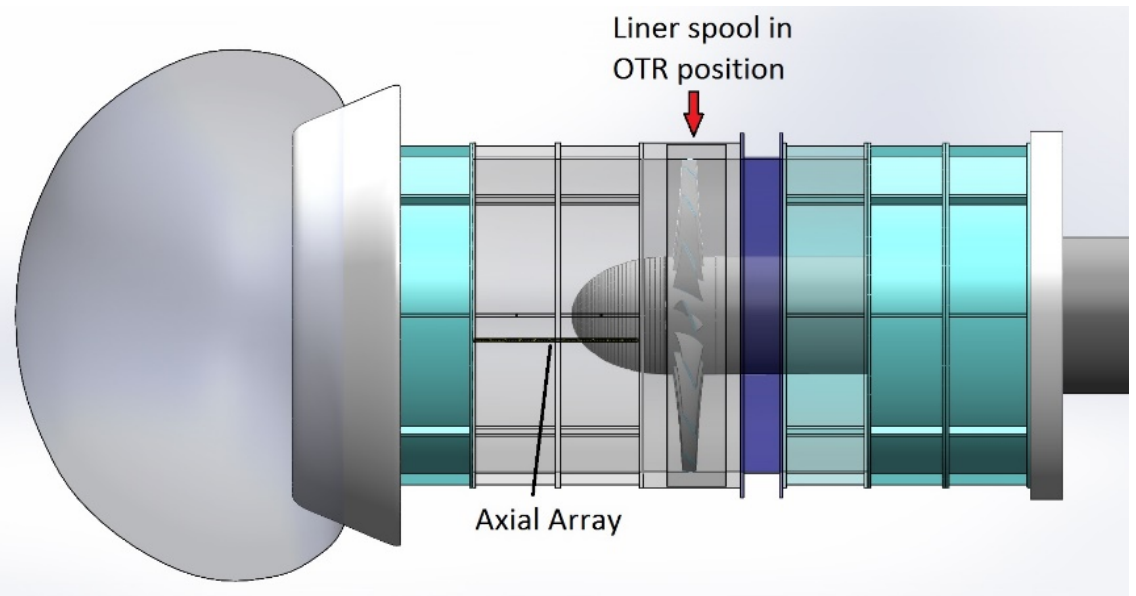

(c) Acoustic Treatment Spool in OTR Position.

Figure 4-ANCF Configurations. 


\section{Instrumentation and Data Acquisition}

Far-field acoustic directivities were processed from the time histories acquired from 30 microphones placed at a $12-\mathrm{ft}$ radius from the duct centerline and 10-ft high. The farfield microphones are grouped into two arcs, one centered and referenced to the inlet acoustic radiation release plane - the second centered and referenced about the exhaust acoustic radiation release plane. This is in contrast to traditional microphone placement, where all microphones are centered and referenced to the fan stacking axis. This arrangement, coupled with the closer radius has been demonstrated to better separate inlet/exhaust fan radiation [8]. The far-field microphone locations are listed in Table II.

When the liner(s) were installed in the inlet position a majority (25) of the microphones were placed in the first arc (inlet centered) in order to better evaluate the farfield directivity and compare to the predictions from the in-duct inlet array measurements (Table IIa). The traditional distribution was used when the liners were tested in the OTR position in order to measure both the forward and aft directivities: Fifteen of these were in an arc about the $\left(0^{\circ}\right.$ to $90^{\circ}$ measured from inlet axis), and fifteen were in an arc about the exhaust acoustic radiation release plane $\left(90^{\circ}\right.$ to $165^{\circ}$ with $180^{\circ}$ being the exit exhaust) (Table IIb). Detailed data processing and analysis of the far-field data are described in Reference 8 .

TABLE II - Far-field Microphone Locations

a. For Liner in Inlet Position.

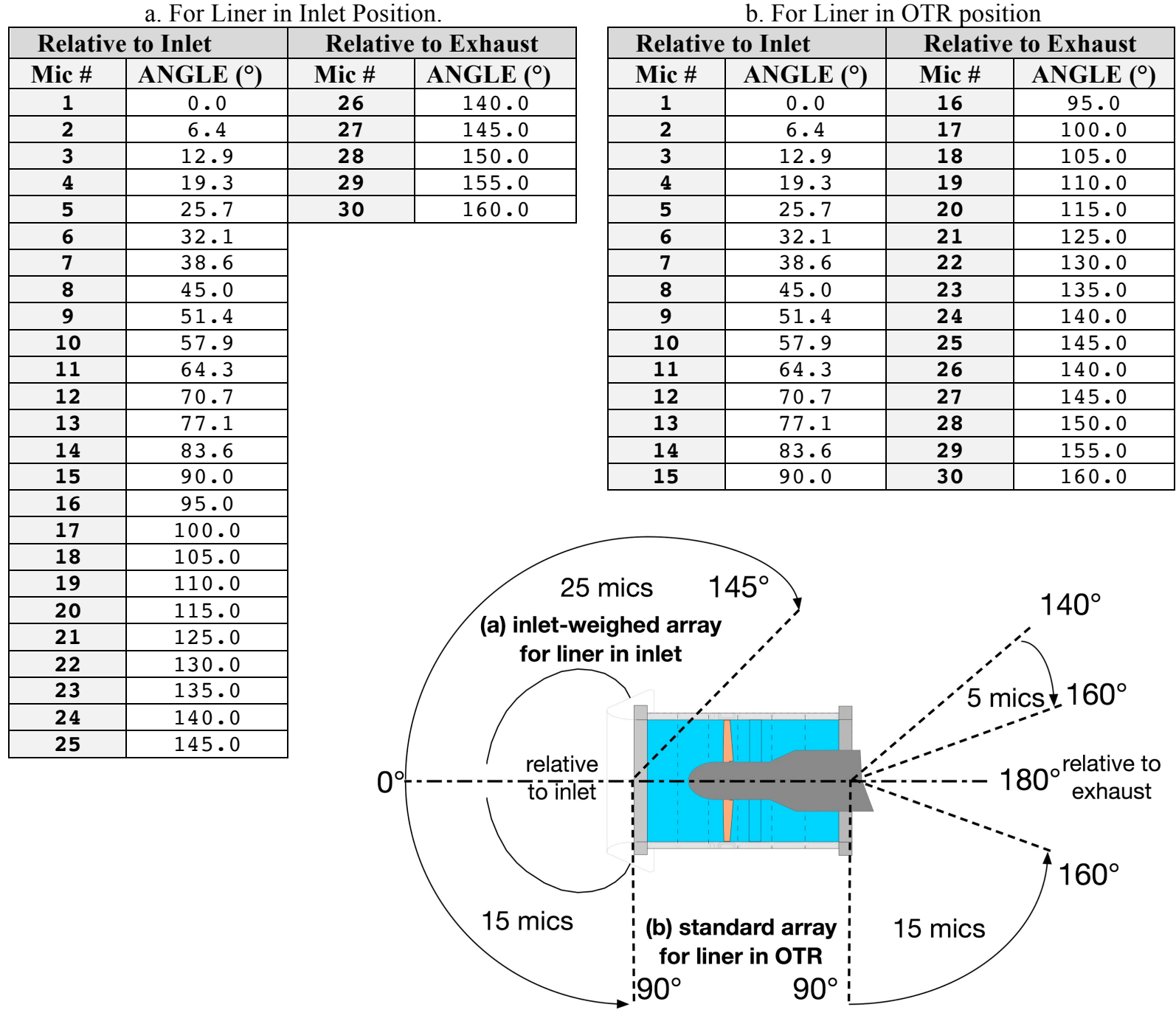


To better understand the physics of the attenuation mechanism, an in-duct microphone array was used for the OTR configurations. The in-duct array strip (Figures $5 \& 6$ ) contained 50 microphones. It was fabricated using rapid prototyping, and was flush-mounted across two cylindrical spools pieces. The microphones in the array strip had uniform spacing, including the span across the spool flanges. The axial array was located at an angle of $261^{\circ}$ in the duct. This angle is referenced from the top-dead-center $\left(0^{\circ}\right)$ in the direction of fan rotation. The fan spins counterclockwise when looking at it from the inlet.

The rapid prototyped in-duct array strip was designed using SolidWorks computer-aided design software. The array had an overall length of 25.25 ", a width of 0.50 ", and a height of $0.50 "$ " The design incorporated fifty 0.16 " diameter holes spaced 0.50 " apart. The tolerances were chosen so the strip secured the microphones. Once the design was finalized, it was strategically separated into four sections within SolidWorks to fit within the build volume limits of the 3D printer. Each section was individually exported as an X3G file, and 3D printed with a MakerBot Replicator 2X using ABS (Acrylonitrile Butadiene Styrene) plastic filament. After each section was printed, the joining ends were dipped in acetone and secured together. Microphones were positioned within the array, and then the in-duct array strip was installed on the ANCF.

The primary systems used during the test runs were far-field microphones, an inlet in-duct linear array system with MOTUs (Precision Filters), an HBM Genesis Data System with PCB mics, and CFANS ${ }^{11}$ in the aft. The tests consisted of running the treatment liner spool in 2 positions while acquiring far-field and in-duct array data over a range of 1400 $-2000 \mathrm{RPM}_{\mathrm{C}}$.
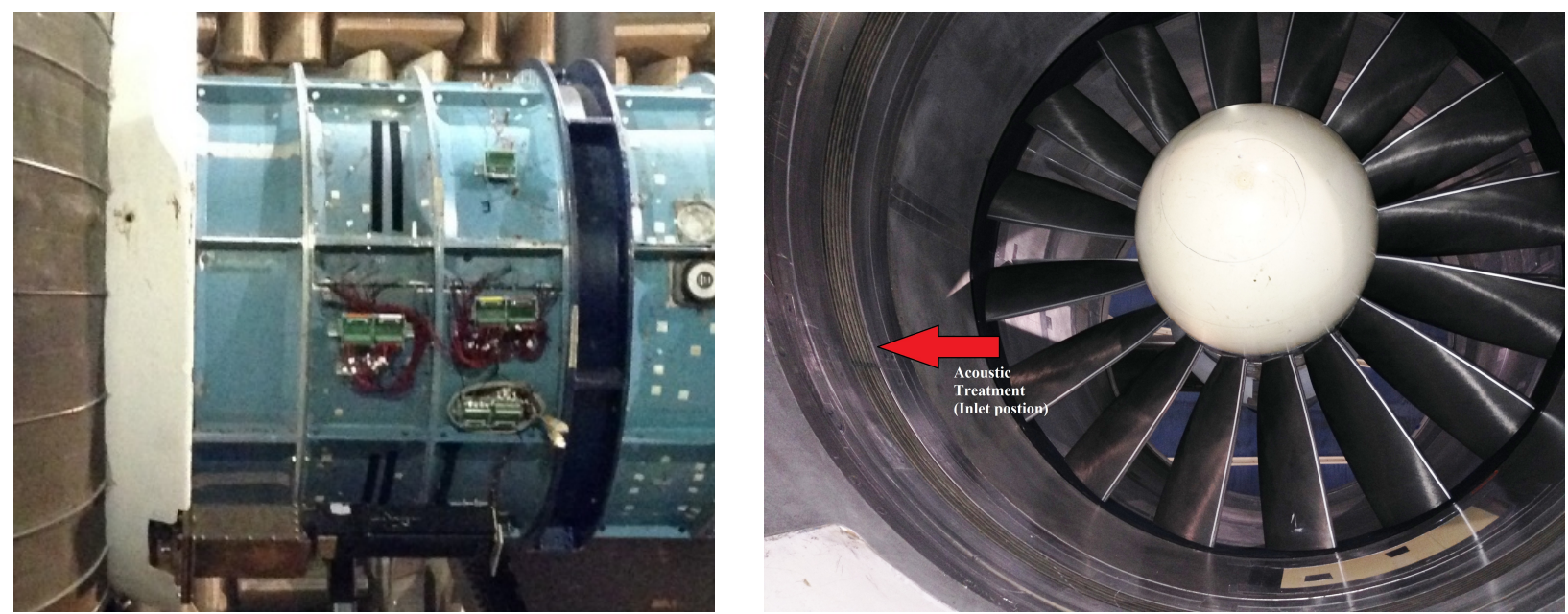

(a) Array Strip Installed on ANCF (External View). (c) Internal View of Acoustic Treatment Spool in Inlet Position.

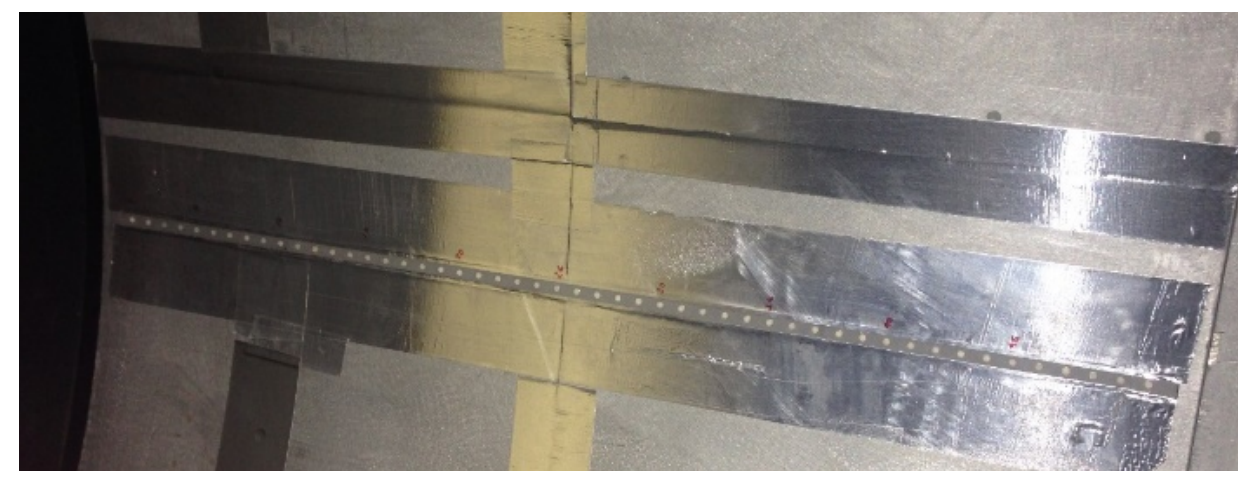

(b) Array Strip Installed on ANCF (Internal View).

Figure 5 - In-Duct Array. 


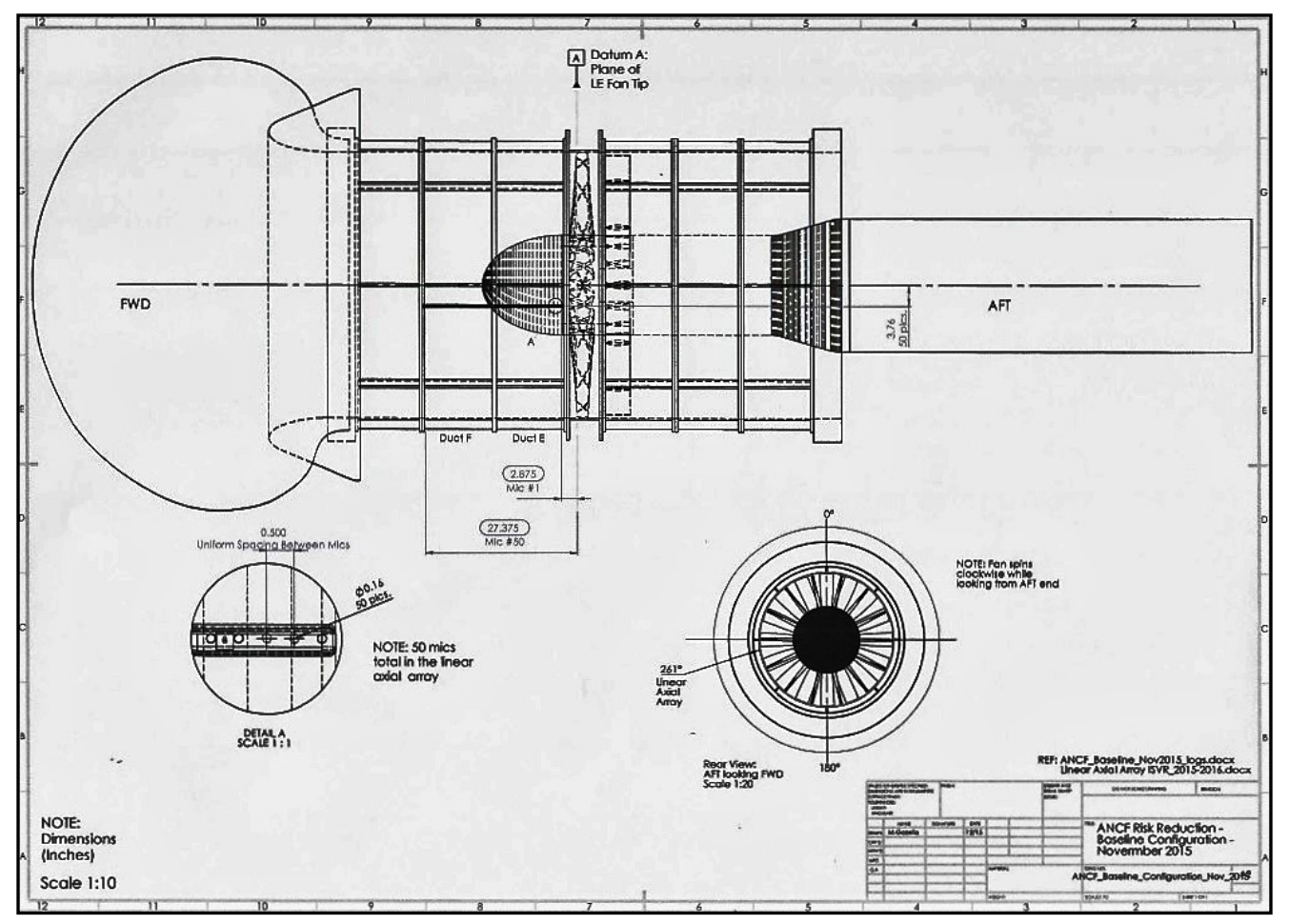

(a) Baseline Configuration.

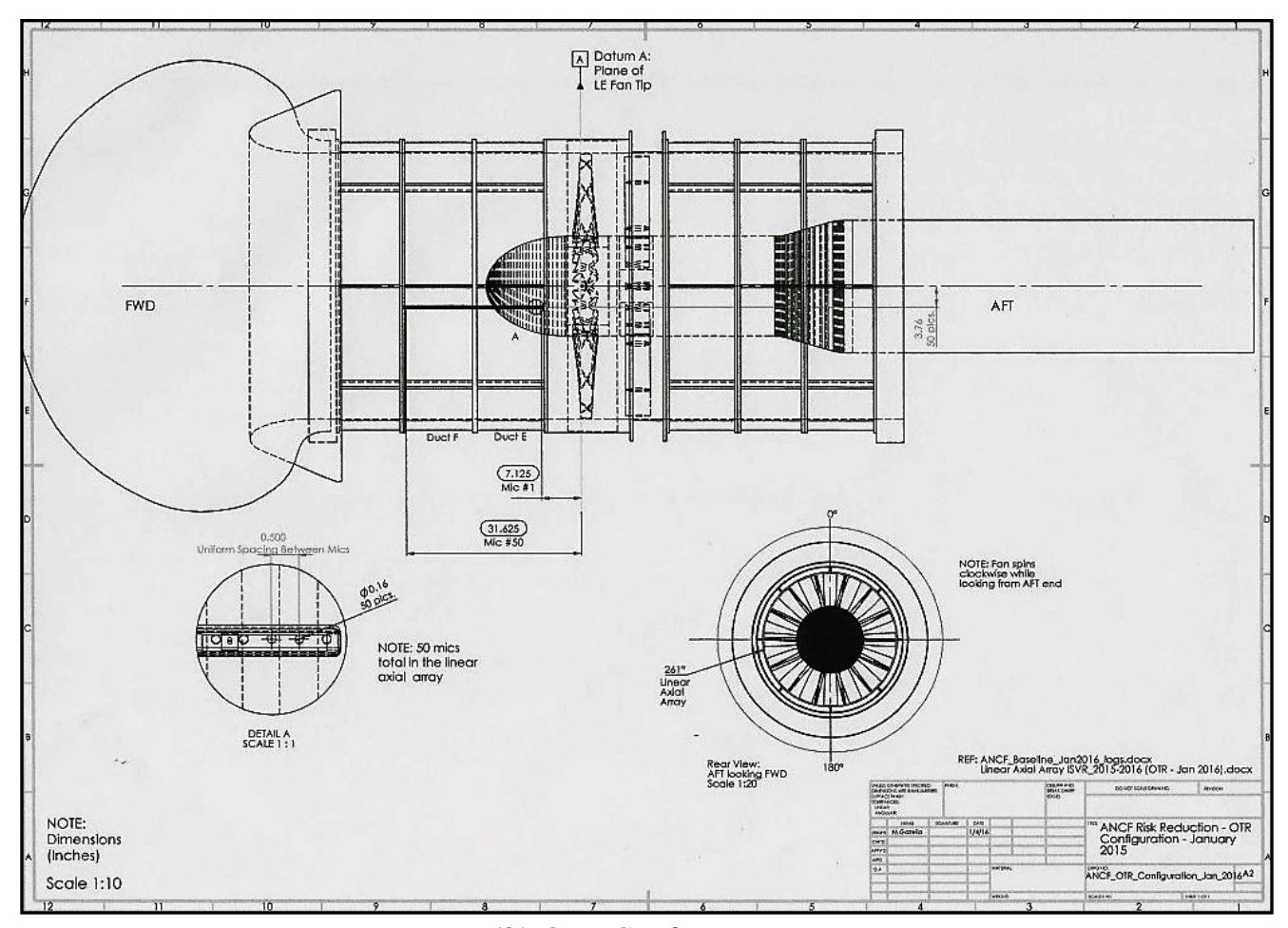

(b) OTR Configuration.

Figure 6-Array Strip Mic Locations in ANCF. 


\section{Data and Results}

\section{A. Far-field}

The following results are provided for all six liner configurations. The data in Figures $7-11$ present the PWL attenuation for each configuration relative to the baseline, at $2000 \mathrm{RPM}_{\mathrm{c}}$. The baseline was chosen to be Configuration II, (hardwall w/ grooves). While this configuration has a different acoustic character than the hardwall without the grooves, referencing to it provides a better indication of the effect of the treatment. For each condition the broadband forward arc - sub-plot (a), and broadband aft arc, - sub-plot (b); and tonal responses forward arc, - sub-plot (c), and tonal aft arc, - sub-plot (d) are presented separately. Each sub-plot has the attenuation for harmonics bands 1-6. A harmonic band is the integration in the frequency band, $1 / 2$-way between harmonics, on both sides of the listed harmonic (see Ref. 8).

Figure 7 presents the attenuation for the various liner configurations in the inlet position, 0 vanes (i.e. rotor-alone). Acoustic attenuation is expected to be a result of direct attenuation of the propagating acoustics from the rotor. Very modest broadband attenuation is measured in the forward arc, just above the measurement uncertainty. Limited attenuation was expected as the axial extent of the treatment is small. Very minor changes in the aft arc are noted, which are within the measurement uncertainty.

Figure 8 presents the attenuation for the various liner configurations in the OTR position, 0 vanes relative to the baseline. Acoustic attenuation is hypothesized to be primarily due to source modification of the rotor, since in this location, propagating acoustics does not apply (near-field). The broadband attenuation in the forward arc general pattern is increasing attenuation with increasing harmonic band. At the low bands, there is a small increase in the PWL, and about $1-1 \frac{1}{2} \mathrm{~dB}$ attenuation in the $5^{\text {th }}$ and $6^{\text {th }}$ harmonic bands. The attenuation achieved by the different configurations is relatively consistent. In the aft arc, the $1^{\text {st }}$ harmonic band shows a slight increase, up to $1.2 \mathrm{~dB}$ for the FML. The broadband PWL attenuation is most noticeable in the $3^{\text {rd }}$ and $4^{\text {th }}$ harmonic bands; up to $3 \mathrm{~dB}$. Modest attenuation $(\sim 1 \mathrm{~dB})$ is achieved at the $5^{\text {th }}$ and $6^{\text {th }}$ bands. The configurations with the thin face sheet appear to have the best performance (III, V, \& VI).

Figure 9 presents the excess attenuation for the various configurations - that is the additional attenuation measured with the treatment OTR compared to that measured with the treatment located in the inlet. This comparison is an attempt to separate the effects of source modification from traditional acoustic wave propagation attenuation. Since very little attenuation was measured with the treatments located in the inlet, the trends are very similar to those measured with the treatment located OTR, especially in the aft arc.

The inclusion of stator vanes behind the rotor provides an additional aeroacoustics source beyond the rotor modification mention earlier. This source could be modified in 2 ways (i) direct attenuation from the forward propagating rotor-stator interaction, and (ii) modification of the rotor aerodynamics affecting the rotor-stator source generation. Figure 10 presents the attenuation for the various configurations in the inlet section, 14 vanes. The attenuations trends are not significantly changed, though configuration V (expansion chamber w/ thin face sheet) has a significant increase at the $1^{\text {st }}$ harmonic band. Perhaps the tip vortex is modified strongly.

Figure 11 presents the excess attenuation for the various configurations with the treatment OTR from 14 vanes compared to 0 vanes (rotor-alone). This analysis could provide insight in to the relative influence of the two physical attenuation mechanisms mentioned in the previous paragraph. Here the differences in the configurations become apparent. Configuration V is shown to have notable increase in noise in both arcs, providing more evidence that the rotor tip vortex has possibly been strengthened - which causes the rotor-stator interaction acoustic source to increase and propagate in both directions. On the other hand, Configuration VI (foam metal w/ thin face sheet) has a slight increase in the attenuation, also noted in both arcs, but more so in the forward arc. This may indicate that the mechanism here is a combination of the two - additional attenuation is achieved by adding that from the rotor source modification to that of the rotor-stator interaction propagating forward over the treatment. 
HW (I)

HW w/ grooves (REFERENCE) (II)

Empty chamber w/ thin face sheet (III)

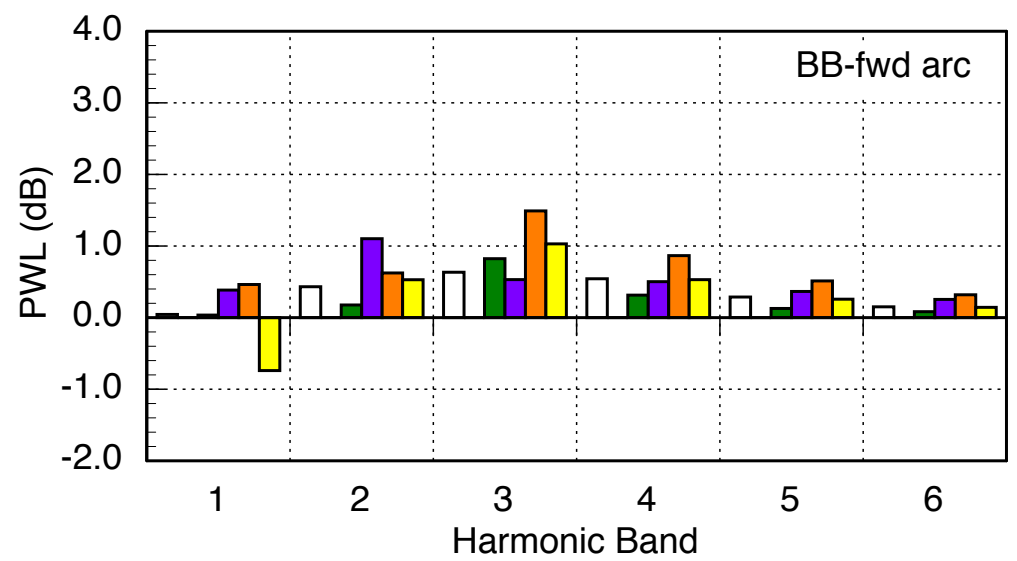

(a) Broadband Attenuation in Forward Far-field Microphone Arc

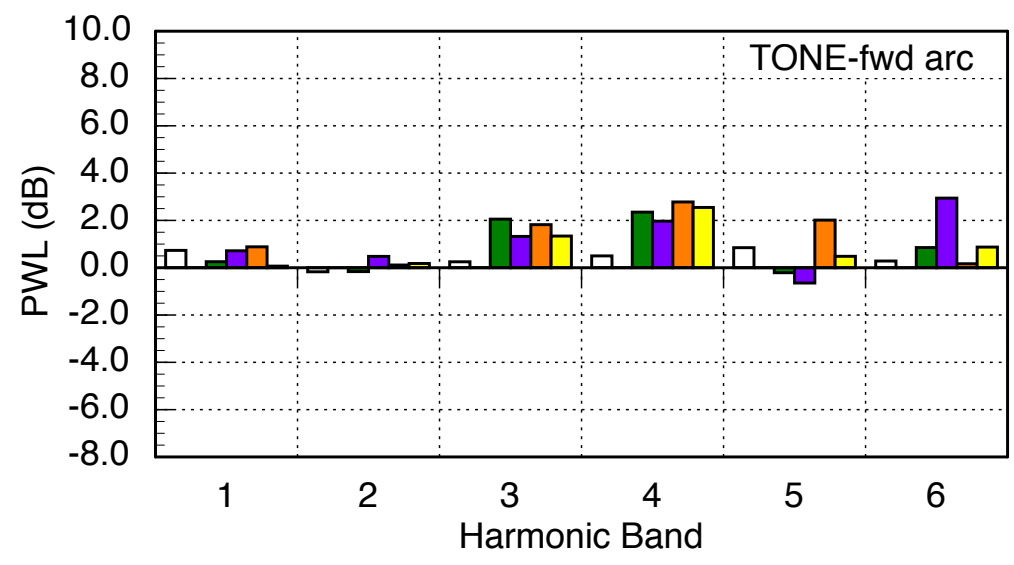

(c) Tonal Attenuation in Forward Far-field Microphone Arc
Empty chamber w/ thick face sheet (IV)

Expansion chamber w/ thin face sheet (V)

Foam Metal w/ thin face sheet (VI)

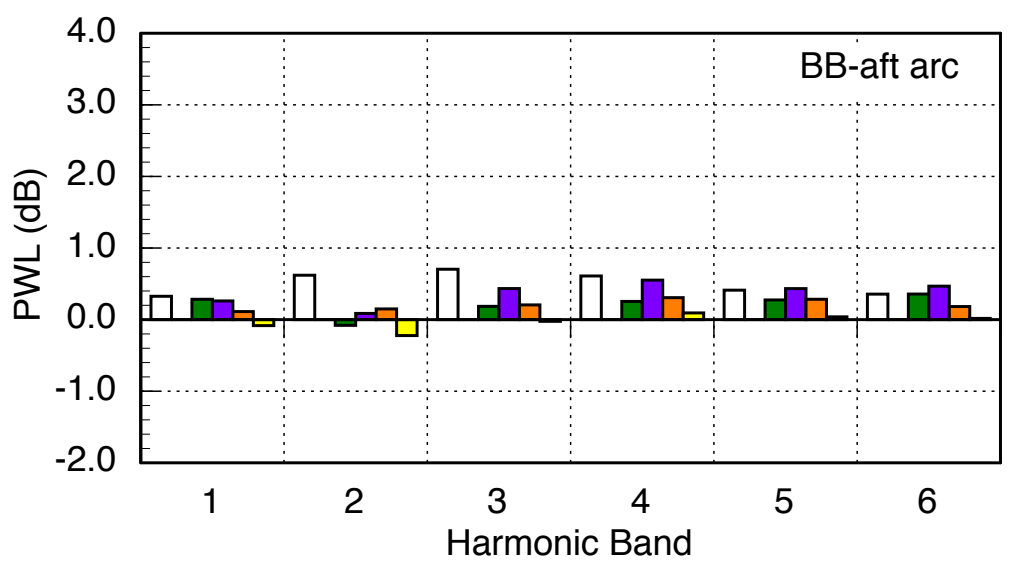

(b) Broadband Attenuation in Aft Far-field Microphone Arc

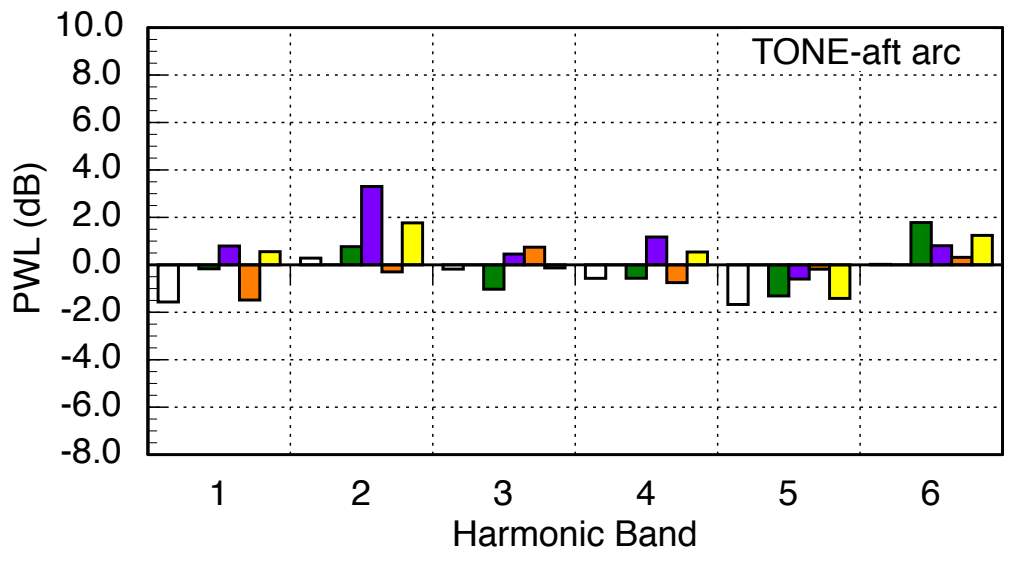

(d) Tonal Attenuation in Aft Far-field Microphone Arc

Figure 7 -Attenuation with Treatment in Inlet $* 2000$ RPM $_{C} * 0$ Vanes. 
HW (I)

HW w/ grooves (REFERENCE) (II)

Empty chamber w/ thin face sheet (III)

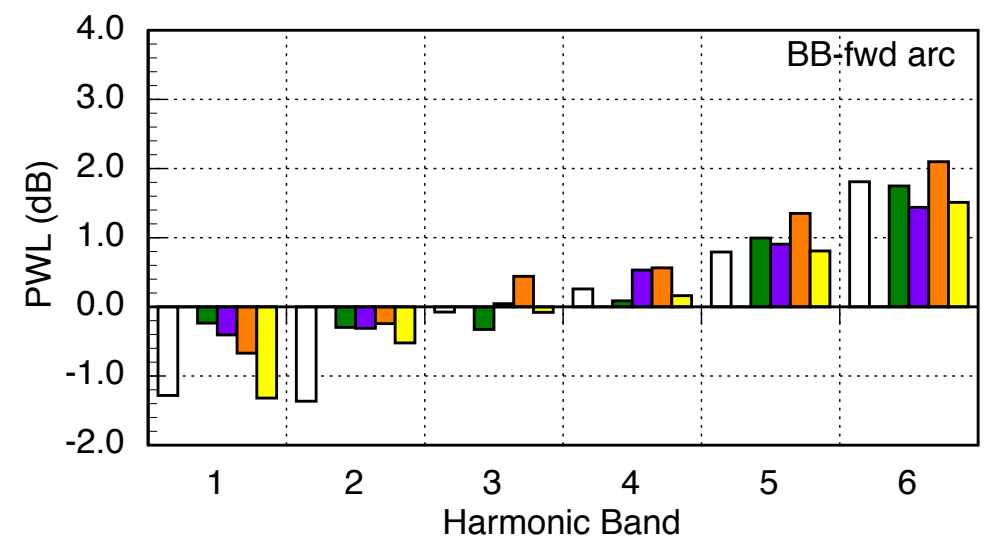

(a) Broadband Attenuation in Forward Far-field Microphone Arc

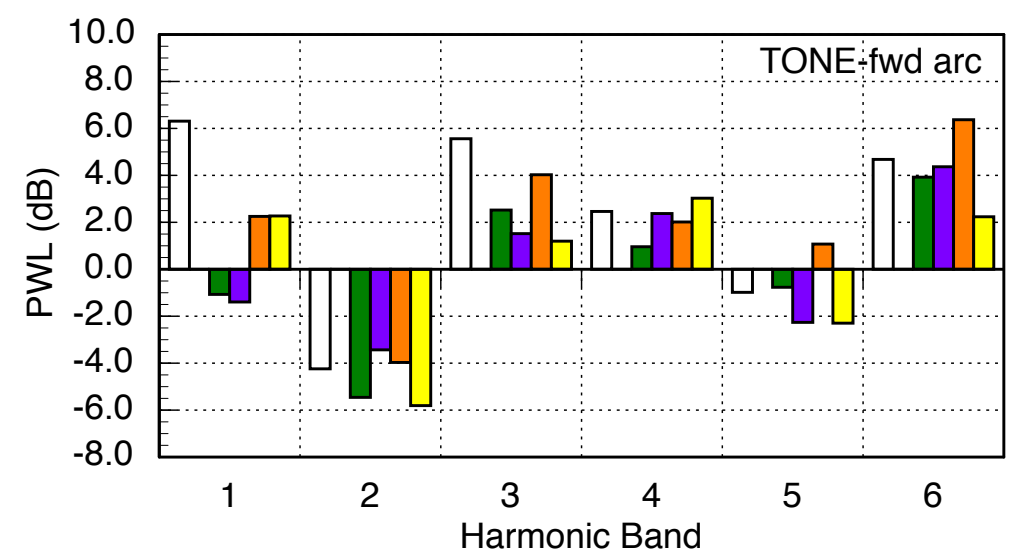

(c) Tonal Attenuation in Forward Far-field Microphone Arc
Empty chamber w/ thick face sheet (IV)

Expansion chamber w/ thin face sheet (V)

Foam Metal w/ thin face sheet (VI)

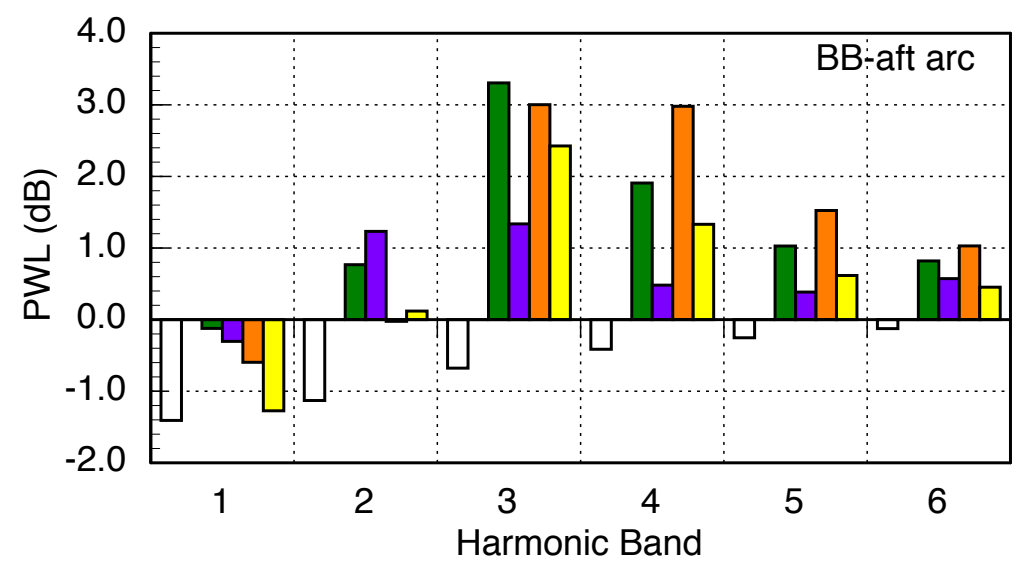

(b) Broadband Attenuation in Aft Far-field Microphone Arc

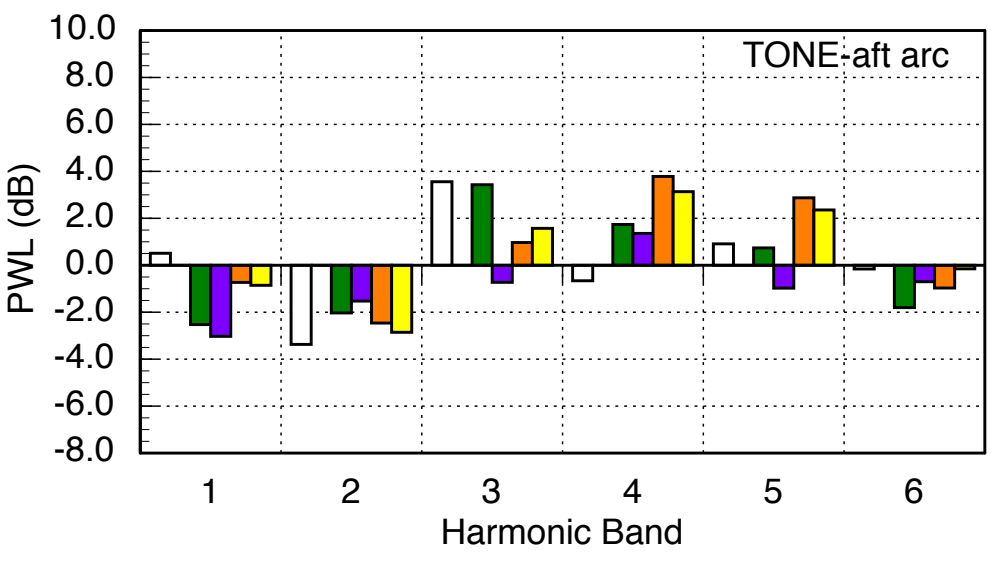

(d) Tonal Attenuation in Aft Far-field Microphone Arc

Figure 8-Attenuation with Treatment in OTR * $2000 \mathrm{RPM}_{C} * 0$ Vanes. 


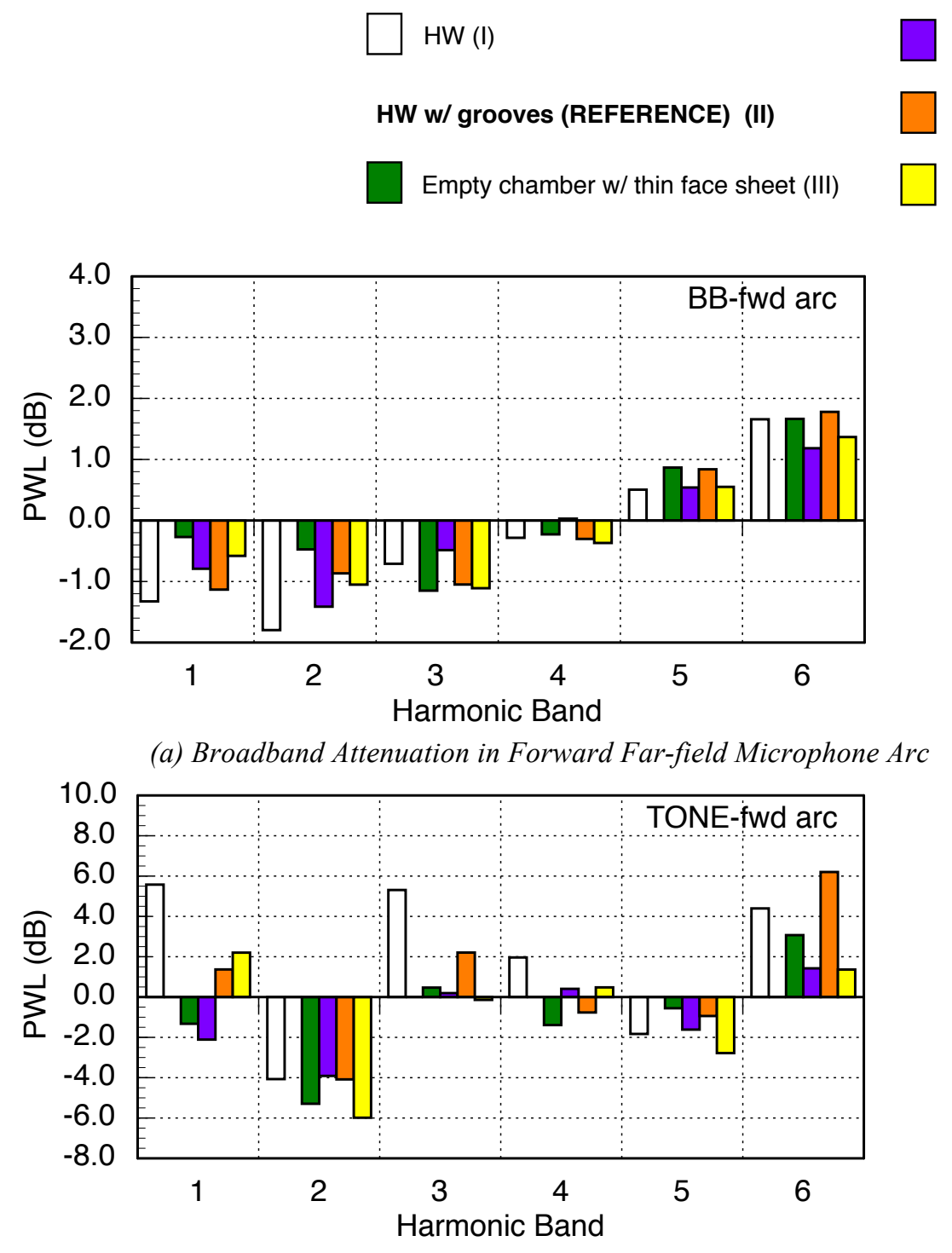

(c) Tonal Attenuation in Forward Far-field Microphone Arc
Empty chamber w/ thick face sheet (IV)

Expansion chamber $\mathrm{w} /$ thin face sheet $(\mathrm{V})$

Foam Metal w/ thin face sheet (VI)

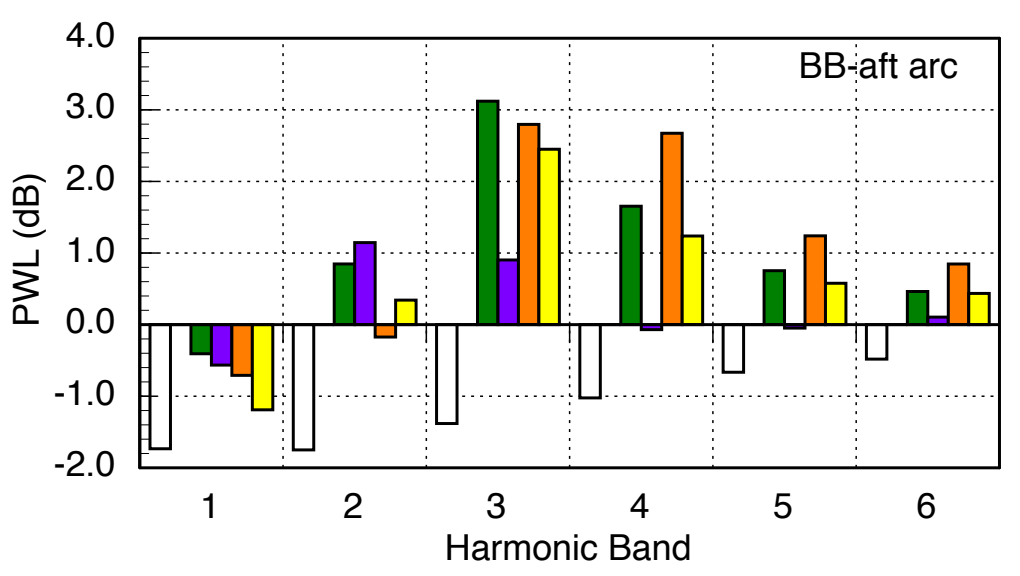

(b) Broadband Attenuation in Aft Far-field Microphone Arc

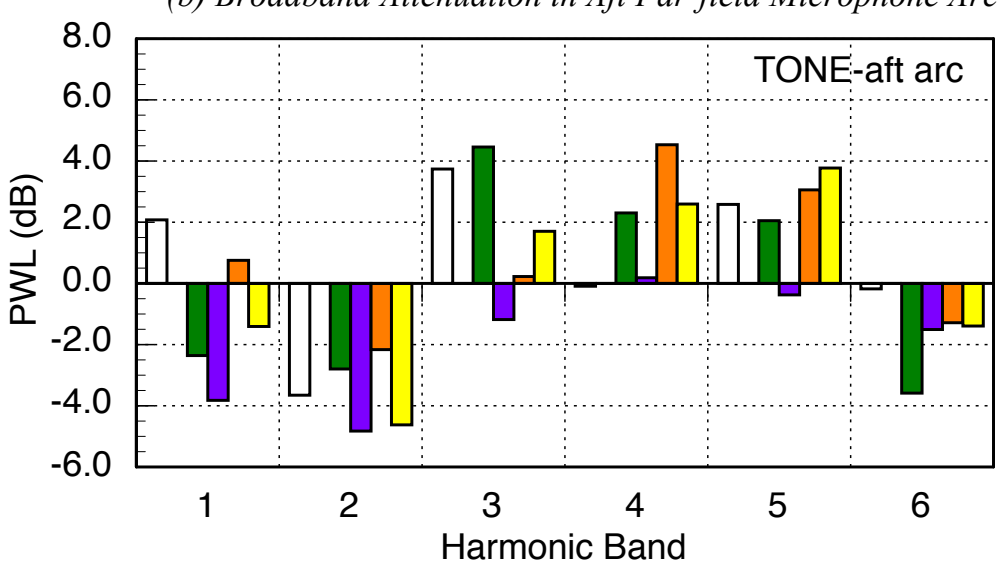

(d) Tonal Attenuation in Aft Far-field Microphone Arc

Figure 9 - Excess Attenuation from OTR Location * 2000 RPM $_{C}$ *0 Vanes. 
HW (I)

HW w/ grooves (REFERENCE) (II)

Empty chamber w/ thin face sheet (III)

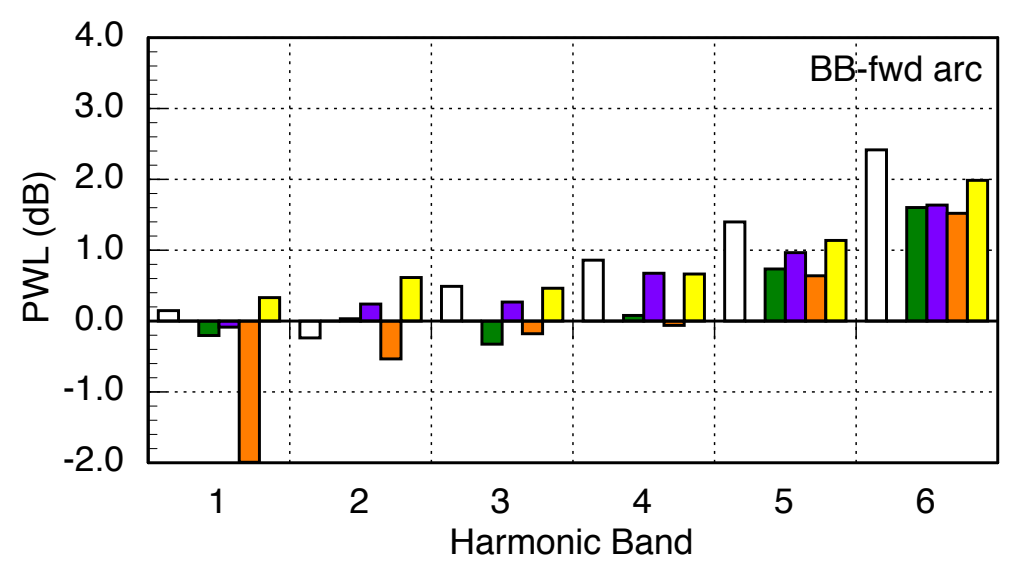

(a) Broadband Attenuation in Forward Far-field Microphone Arc

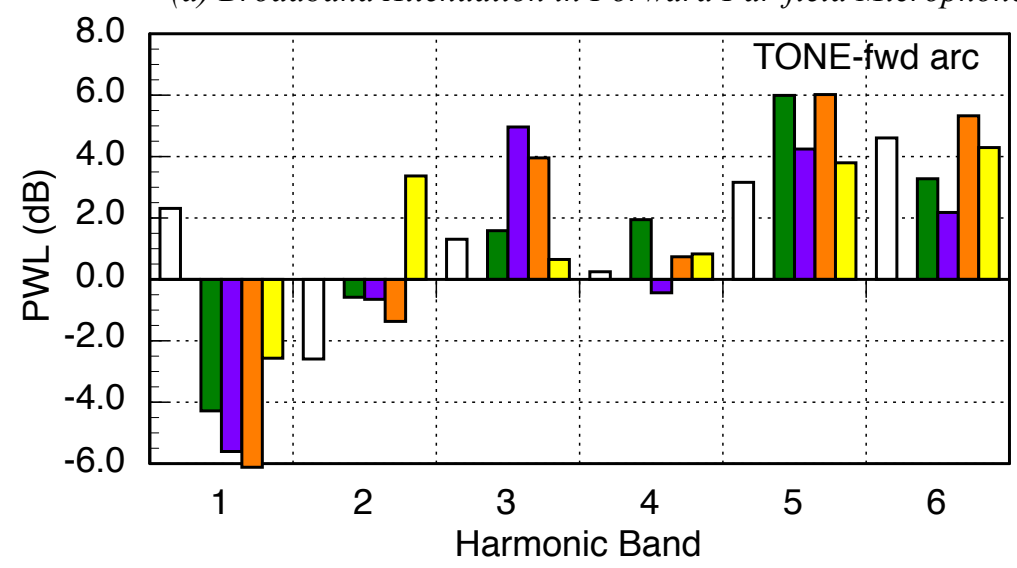

(c) Tonal Attenuation in Forward Far-field Microphone Arc
Empty chamber w/ thick face sheet (IV)

Expansion chamber w/ thin face sheet (V)

Foam Metal w/ thin face sheet (VI)

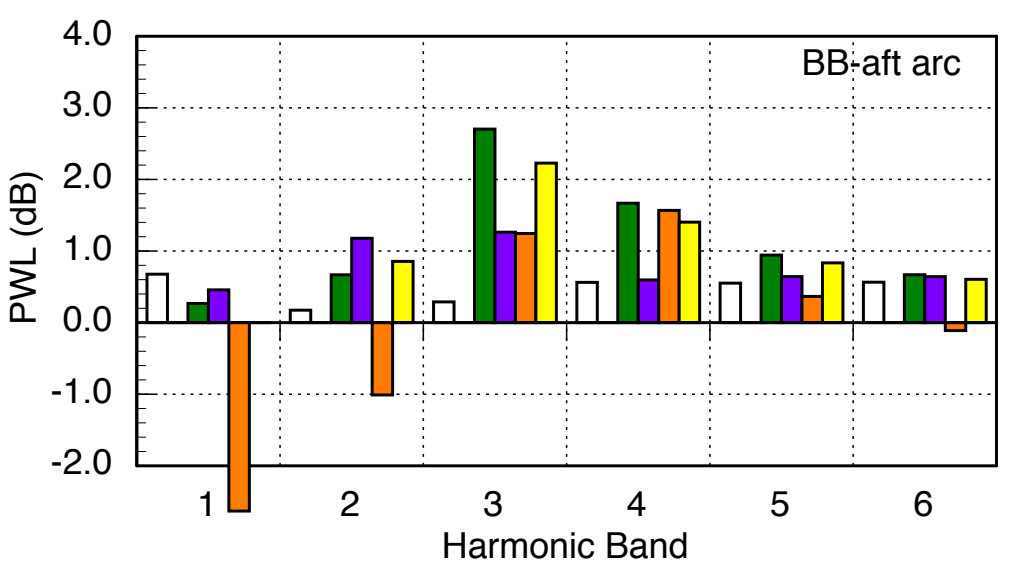

(b) Broadband Attenuation in Aft Far-field Microphone Arc

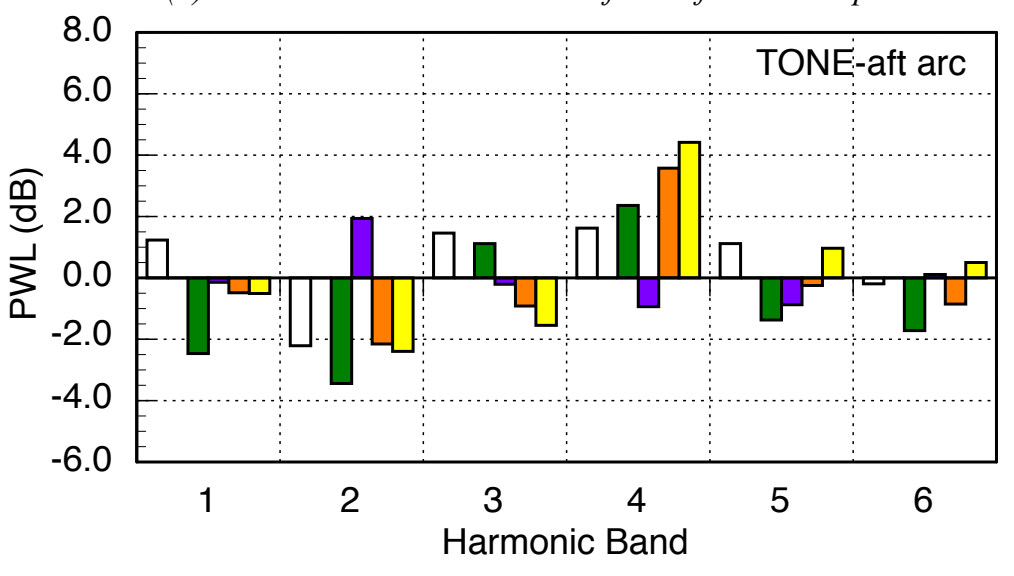

(d) Tonal Attenuation in Aft Far-field Microphone Arc

Figure $10-$ Attenuation with Treatment in OTR * $2000 \mathrm{RPM}_{C} * 14$ Vanes. 
HW w/ grooves (REFERENCE) (II)

Empty chamber w/ thin face sheet (III)

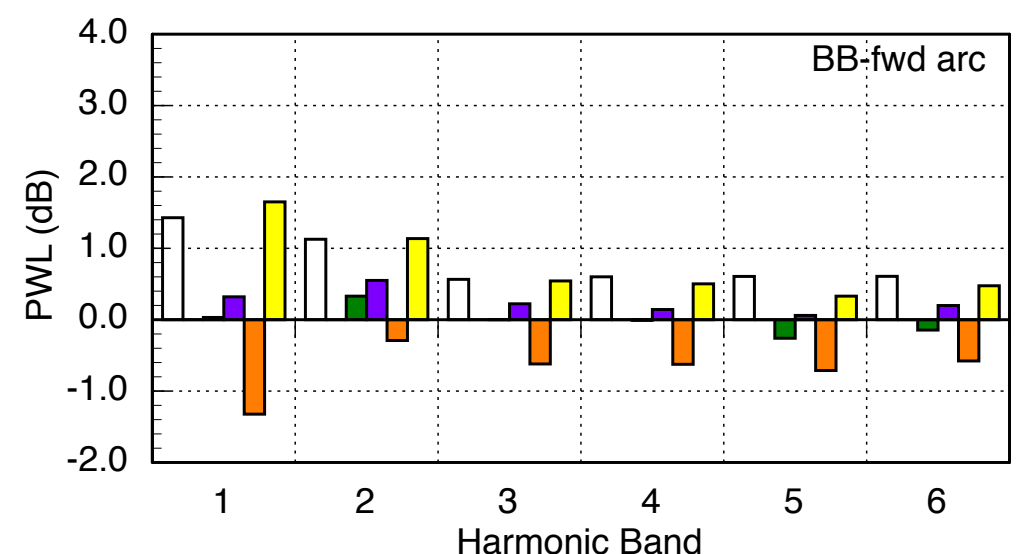

(a) Broadband Attenuation in Forward Far-field Microphone Arc

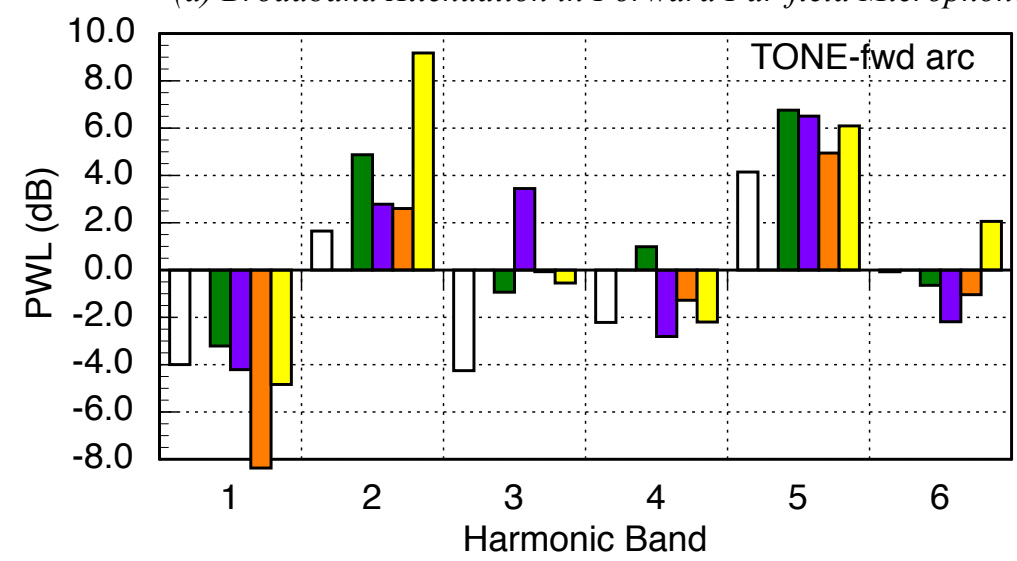

(c) Tonal Attenuation in Forward Far-field Microphone Arc
Empty chamber w/ thick face sheet (IV)

Expansion chamber $\mathrm{w} /$ thin face sheet $(\mathrm{V})$

Foam Metal w/ thin face sheet (VI)

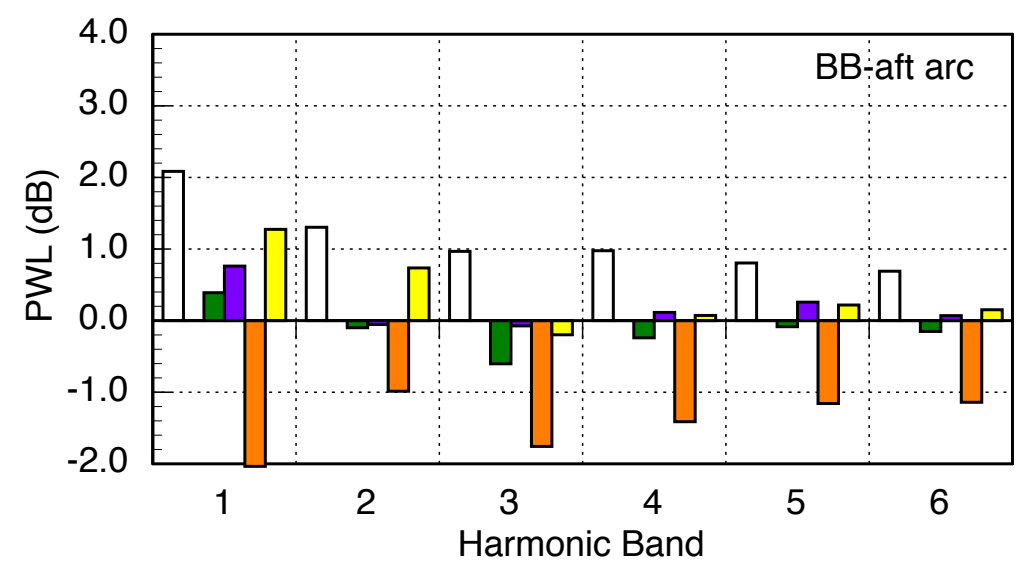

(b) Broadband Attenuation in Aft Far-field Microphone Arc

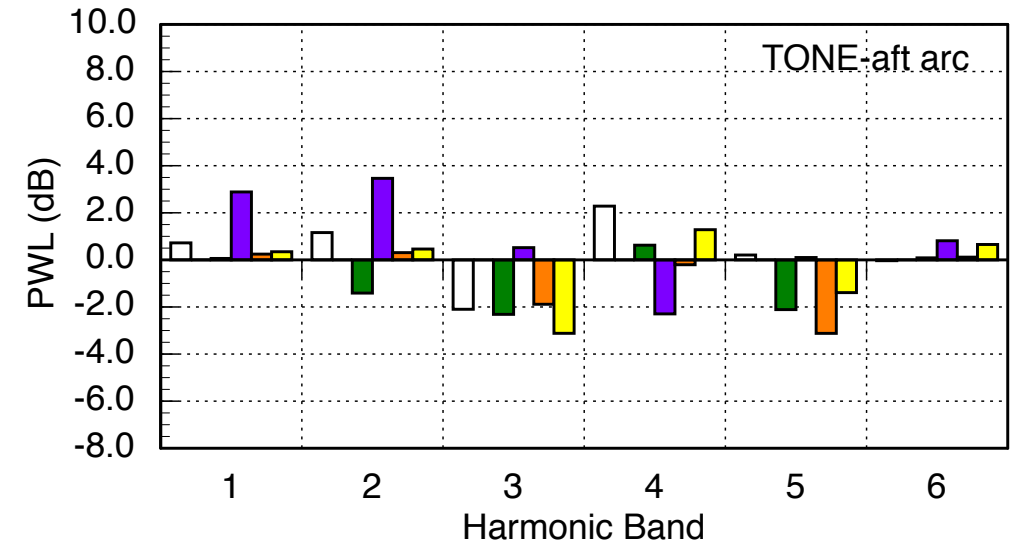

(d) Tonal Attenuation in Aft Far-field Microphone Arc

Figure 11 - Excess Attenuation from 14 Vanes $* 2000$ RPM $_{C} *$ OTR Location. 


\section{B. In-Duct Array}

An in-duct to far-field beam-former method has been developed at the $\mathrm{ISVR}^{6}$ which takes a measurement of the beam-former output from an in-duct axial array (see Figure 5b) and using a theoretical in-duct to far-field transfer function, projects the beam former output to the far-field. The theoretical transfer function has been computed using the ACTRAN ${ }^{\mathrm{TM}}$ code and a statistically-uniform distributed axial dipole source model.

The method has been undergoing extensive validation for aft-arc radiation, for which it was originally designed, but the data taken in these current ANCF tests presented the opportunity of validation in the forward arc for fan inlet noise, along with a much-improved axial array (see Figures $4 \& 5$ ).

In the following two figures the measured far-field forward arc PWL is shown over the frequency range $500 \mathrm{~Hz}$ to $4 \mathrm{kHz}$ (or slightly less, depending on the digitization) for four fan speeds $(1400,1600,1800$ and $2000 \mathrm{RPM}$ corrected) and compared with the beam-former projections. The corresponding axial Mach numbers used in the induct to far-field transfer function calculation are [0.1 0.120 .1350 .15$]$.

A comparison of the PWL and that projected from beamforming ${ }^{6}$ for the hardwall (hardwall w/ grooves Configuration II, the same reference as used in figures above) is shown in Figure 12(a) and for the OTR liner Configuration VI (in the OTR position) in Figure 12(b), both with no vanes. The agreement is generally good for the OTR liner above $1 \mathrm{kHz}$ while the significant differences below $1 \mathrm{kHz}$ are probably due, at least in part, to resolution limitations of the array (defined by the array length and wavelength). The agreement is less satisfactory for the hardwall w/ grooves in Figure 12 (a) but the measured trends are captured apart from the low frequency deviations.

In Figure 12(c) the difference in the PWL spectrum of the measured data i.e. between Configurations II and VI, yields the PWL insertion loss spectrum, a direct measure of the OTR liner noise suppression performance, for the four RPM test conditions. The consistency in the PWL insertion loss spectra is quite remarkable, varying from $-1 \mathrm{~dB}$ at low frequency to $+2 \mathrm{~dB}$ at high frequency, almost independent of speed. This is not captured quantitatively in the predicted PWL insertion loss spectra in Figure 12(d) but again the trend is about right, in fact a simple -1 dB shift applied to the predictions would bring these into line.

The generally good agreement above $1 \mathrm{kHz}$ between the measured and projected PWL from this ANCF fan inlet data is a useful validation of the beam-former method for broadband fan inlet noise in the forward arc. More detailed comparisons, in particular of the measured and projected SPL directivities, will be reported elsewhere in the near future. 

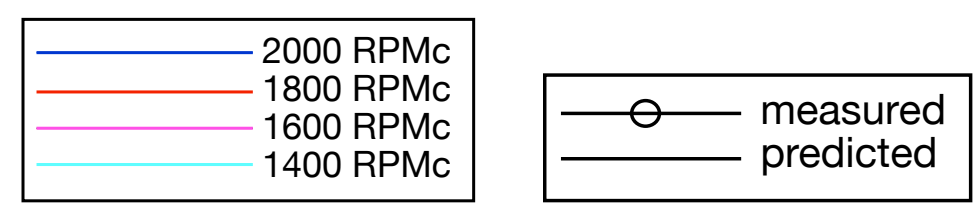

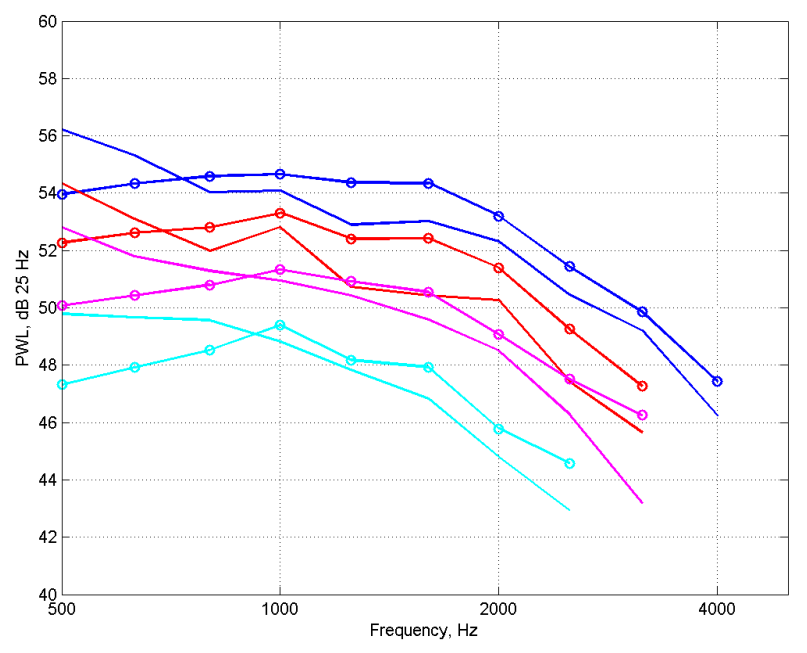

(a) Hardwall w/ grooves - Configuration II

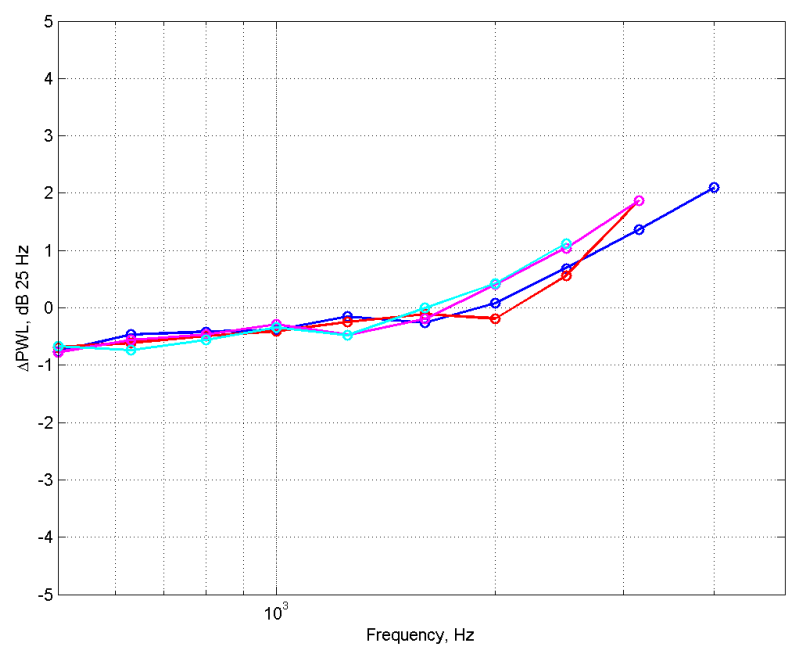

(c) OTR Measured PWL insertion loss

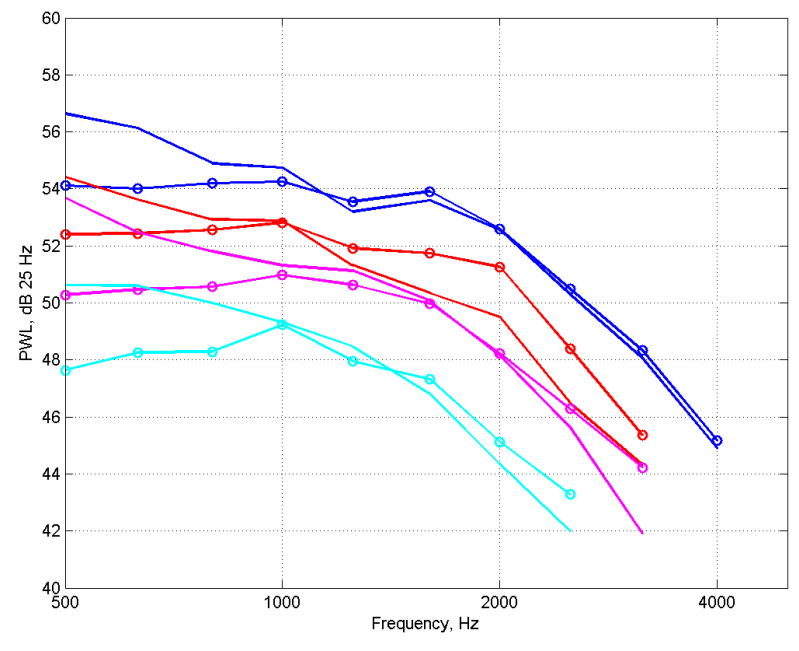

(b) OTR-Configuration VI

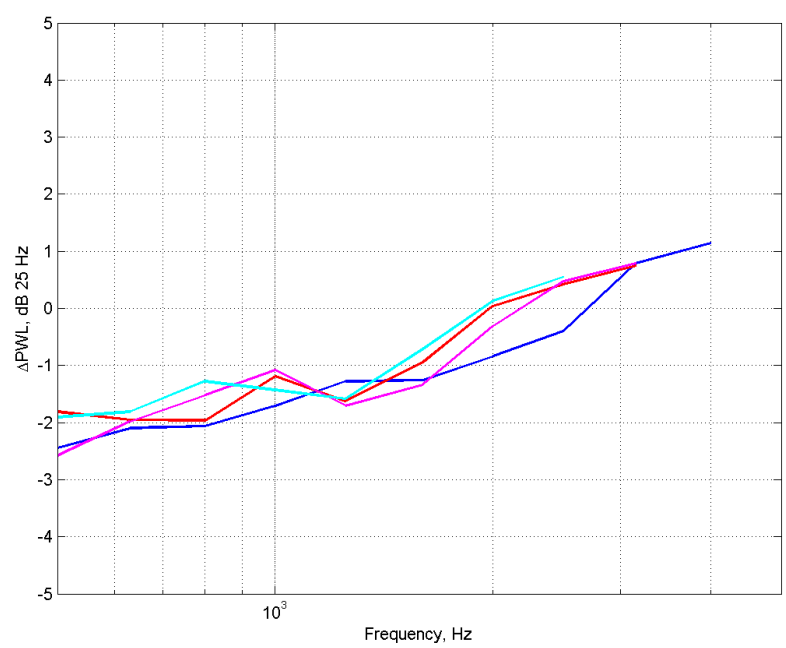

(d) OTR Predicted PWL insertion loss

Figure 12 - Measured and Predicted Far-field PWL Spectra for OTR Configuration VI, reference Hardwall w/ grooves Configuration II; no vanes. 


\section{Conclusion}

Several novel acoustic treatments were designed and tested on a low-speed ducted-fan, the NASA Glenn AdvancedNoise Control Fan. Two positions were tested, (i) in a traditional inlet location, and (ii) in an over-the-rotor location. The hardwall with grooves configuration was used as a reference to compare the effect of the other treatments described in the paper. The treatment had minimal effect while placed in the inlet position compared to the baseline configuration with no treatment due to the minimal axial extent. In the OTR position, several of the liner designs were shown to have a reduction on the fan noise. While comparing the hardwall with grooves treatment to the HW showed that the tonal content is higher, but the broadband noise is reduced by about $1 \mathrm{~dB}$ in the forward and $3 \mathrm{~dB}$ the aft. Although there is typically an aerodynamic penalty associated with hardwall with grooves, this type of treatment has an added benefit of stall margin extension. Therefore, a system consideration of this treatment option should be viewed when an OTR treatment is implemented.

Significant attenuation of several of the treatment designs were measured when installed in the OTR position. The biggest factor appeared to be the face sheet, with the thinner face sheet achieving up to $3 \mathrm{~dB}$ of attenuation in the midfrequency range $\left(3-4^{\text {th }}\right.$ harmonic). The empty chamber, expansion chamber, and foam metal inserts performed approximately similar when coupled with the thin face sheet. The increased attenuation relative to inlet position indicates the attenuation mechanism can be attributed to source modification.

The comparison of the reduction achieved in a rotor-alone vs rotor-stator indicated that the attenuating mechanism is a combination of source modification plus a reduction in the propagating acoustic wave from the rotor-stator interaction, which is very notable in the forward arc. An important observation is that, for some treatments, the noise is increased, probably due to a modification in the rotor tip vortex impinging on the stator vanes.

In addition, these series of tests assured that the acoustic treatments can be successfully installed and tested, therefore reducing the risk of such treatments while being tested in the W8 Single-Stage Axial Compressor Facility at NASA Glenn Research Center in the near future.

These measurements were also used to provide validation of an in-duct to far-field beam-former fan broadband noise prediction method. Very good agreement between far-field measured and predicted PWL data above $1 \mathrm{kHz}$ was demonstrated.

\section{Acknowledgments}

The authors would like to acknowledge the dedication and professionalism of the technicians and engineers of the Acoustics Branch and the Aero-Acoustic Propulsion Laboratory and the design efforts of James Buckley, Vantage Partners. This work was funded by the NASA Advanced Air Transportation Technology project and by the AeroAcoustics Research Consortium.

\section{References}

\footnotetext{
${ }^{1}$ Jones, M.G., Parrott, T.L., Sutliff, D.L., and Hughes, C.E., “Assessment of Soft Vane and Metal Foam Engine Noise Reduction Concepts", AIAA-2009-3142.

${ }^{2}$ Elliott, D.M., Woodward, R.P., Podboy, G.G., “Acoustic Performance of Novel Fan Noise Reduction Technologies for a High Bypass Model Turbofan at Simulated Flight Conditions,” AIAA 2009-3140.

${ }^{3}$ Hughes, C.E., Gazzaniga, J.A., "Effect of Two Advanced Noise Reduction Technologies on the Aerodynamic Performance of an Ultra High Bypass Ratio Fan," AIAA 2009-3139.

${ }^{4}$ Sutliff, D. L., \& Jones, M. G., "Low-Speed Fan Noise Attenuation from a Foam-Metal Liner", Journal of Aircraft, (2009).

${ }^{5}$ Sutliff, D. L., Jones, M.G., Hartley, T. C. "High-Speed Turbofan Noise Reduction Using Foam-Metal Liner Over-the-Rotor", International Journal of Aeroacoustics, (2013).

${ }^{6}$ Tester, B. J., Özyörük, Y., Sutliff, D. L., and Bozak, R. F.,’Validation of an in-duct to far-field beamformer method for predicting far-field fan broadband noise," AIAA 2016-2894, AIAA Aeroacoustics Conference, Lyon, France, 2016

${ }^{7}$ Loew, R. A., Lauer, J. T., McAllister, J., \& Sutliff, D. L., “The Advanced Noise Control Fan,” AIAA-2006-3150, Nov 2006.

${ }^{8}$ McAllister, J., Loew, R. A., Lauer, J. T., \& Sutliff, D. L., “The Advanced Noise Control Fan Baseline Measurements," AIAA Paper 2009-0624, October 2009. NASA Glenn Research Center. (2008, October 21).

9 Bozak, R. F. “Advanced Noise Control Fan Aerodynamic Performance," NASA TM 2009-215807, November 2009.

${ }^{10}$ Cooper, B.A., "A Large Hemi-Anechoic Chamber Enclosure for Community-Compatible Aeroacoustic Testing of Aircraft Propulsion Systems," Journal of the Institute of Noise Control Engineering of the USA, Jan/Feb 1994.

${ }^{11}$ Sutliff, D.L. and Walker, B.E., "Artificial Noise Systems for Parametric Studies of Turbo-machinery Aero-acoustics", International Journal of Aeroacoustics, 2016, Vol. 15(1-2) 103-130.

${ }^{12}$ Bozak, R., Hughes, C., and Buckley, J., "The Aerodynamic Performance of an Over-the-Rotor Liner with Circumferential Grooves on a High Bypass Ratio Turbofan Rotor," ASME GT2013-95114, June 2013.
} 